\title{
Usos sociais do patrimônio cultural (natural) e participação democrática em áreas protegidas
}

\section{Filipe Vieira de Oliveira ${ }^{1}$}

\begin{abstract}
1 Doutorando em Ciência Ambiental - PROCAM/USP, Mestre em Ciências pela Escola de Artes, Ciências e Humanidades da Universidade de São Paulo. É especialista em Gestão Pública de Controle e Educação Ambiental pela Universidade Federal de São Paulo. Graduado em Gestão de Turismo pelo Instituto Federal de Educação, Ciência e Tecnologia de São Paulo. Professor da Universidade Federal do Tocantins, Brasil. E-mail: filipeoliveira@usp.br
\end{abstract}

RESUMO: Apresentamos neste ensaio teórico uma reflexão acerca das perspectivas de usos sociais do patrimônio cultural (natural) em áreas protegidas no Brasil e os desafios inerentes da participação democrática na tomada de decisões em espaços protegidos, neste caso, especificamente nas Unidades de Conservação de Proteção Integral em que existam populações residentes. $O$ texto apresenta algumas considerações sobre a noção bastante ambígua no entendimento de patrimônio cultural e natural. Refletimos também, sobre o que seriam usos sociais mais adequados à salvaguarda do patrimônio cultural e natural em áreas protegidas que considerem a relação homem natureza. Verificamos, portanto, que a não participação na instituição de patrimônios não corroboram para a efetividade da proteção nem das possibilidades de sobrevivência das comunidades que habitam estes espaços. É preciso pensar políticas que considerem estes conflitos entre o preservacionismo e as necessidades de subsistência das populações, sem desconsiderar os riscos e ameaças para o meio ambiente e para os seres humanos.

Palavras-chave: Patrimônio cultural e natural; Áreas protegidas; participação social.

\section{Social uses of cultural (natural) heritage and democratic participation in protected} areas

\begin{abstract}
We present in this theoretical essay a reflection on the perspectives of social uses of the (cultural) natural heritage in protected areas in Brazil and the inherent challenges of democratic participation in decision making process in protected spaces, in this case specifically in the Integral Protection Conservation Units in that there are resident populations. The text presents some considerations about the rather ambiguous notion in the understanding of cultural and natural heritage. We also reflect on what would be the most appropriate social uses to safeguard cultural and natural heritages in protected areas, and to consider the relationship between man and nature. We have verified, therefore, that the non-participation in the institution of heritages does not corroborate for the effectiveness of the protection nor for the possibilities of survival of the communities that inhabit these spaces. It is necessary to think of policies that consider these conflicts between preservationist and the need of subsistence of the populations, without ignoring the risks and threats to the environment and humans.
\end{abstract}

Keywords: Cultural and natural Heritage; Protected areas; Social participation.

\section{INTRODUÇÃO}

Este ensaio traz algumas reflexões sobre os usos sociais do patrimônio natural, es- 
pecificamente nas áreas protegidas do Brasil que se inserem dentro do modelo de gestão do Sistema Nacional de Unidades de Conservação (SNUC), e a participação democrática na tomada de decisões sobre as políticas de uso e salvaguarda do patrimônio, principalmente nas Unidades de Conservação de Proteção Integral.

A criação de uma área protegida, que em nosso entendimento se assemelha a instituição de um patrimônio pressupõe a possibilidade de perda de um bem considerado importante para a sociedade ou para determinados grupos sociais onde se adverte uma percepção de risco, seja na dimensão cultural ou ambiental e que se tem a premissa da necessidade de elaboração de políticas públicas para a efetividade da salvaguarda do patrimônio, representado tanto por espaços protegidos quanto pelo patrimônio cultural referente a interação do homem com a natureza.

No Brasil, não é comum a formulação de políticas conjuntas de salvaguarda do patrimônio. Os instrumentos de proteção recaem sob a responsabilidade de instituições distintas. No âmbito Federal, por exemplo, o patrimônio cultural (material, imaterial ou natural) está sob o escudo do Instituto do Patrimônio Histórico, Artístico Nacional (IPHAN), e as Unidades de Conservação da Natureza sob a égide do Instituto Chico Mendes de Conservação da Biodiversidade (ICMBIO), que, a nosso ver, devido aos critérios de seleção lhes dá uma conotação preservacionista, onde a natureza deve ser 'protegida do homem', muitas vezes, desconsiderando a existência de populações dentro das áreas protegidas.

A diferença se faz presente, no caso do patrimônio natural, no entendimento de cada instituição quanto as características do que considera-se essencial para a proteção dos lugares de grande valor, que, tanto para o IPHAN quanto para o ICMBIO é o conteúdo preservacionista que se dá ao ambiente natural, seja por suas características estéticas, físicas, biológicas, científicas, mas que, notadamente, as experiências de conservação não se mostram suficientes para garantir a salvaguarda do ambiente natural e corroboram com conflitos socioambientais por não garantirem usos que possam suprir as necessidade de proteção da natureza e de desenvolvimento econômico e social, muito menos a participação democrática na tomada de decisões sobre a instituição desses patrimônios.

Esta confusão emerge desde a convenção da Organização das Nações Unidas para a educação, a ciência e a cultura (UNESCO) para o a proteção do patrimônio mundial, cultural e natural de 1972. A convenção estabeleceu a inscrição de bens em duas categorias diferentes, o patrimônio natural e o patrimônio cultural. De acordo com Santilli (2010, s.p.), "havia no texto da convenção, um antagonismo entre as categorias cultural e natural, reflexo da origem bipartite da preocupação com o patrimônio mundial, oriunda de dois movimentos separados: um que se preocupava com os sítios culturais e outro que lutava pela conservação da natureza".

Nesse sentido, propomos um olhar sobre as possibilidades de usos sociais do patrimônio natural em Unidades de Conservação com o intuito de contribuir para a construção do debate acerca da urgência ambiental em uma sociedade em que o ris- 
co de perda é sempre iminente, e da importância do patrimônio natural e das áreas protegidas que também se encontram sob ameaça por não garantirem usos mais adequados à sua condição de bem comum e de grande valor para a sociedade e que concentram grandes entraves socioambientais, e também, relacionar as dificuldades de participação das comunidades na tomada de decisões sobre a instituição e gestão do patrimônio natural.

Entendemos como uso social do patrimônio, as possibilidades de relacionar os bens de grande valor para a sociedade ás necessidades atuais, pois, observamos que a simples instituição de "patrimônios" não garante a sua efetiva proteção. GarciaCanclini (1999), um dos maiores estudiosos do tema, defende a apropriação cultural do patrimônio onde se veem outras oportunidades de usos, não degradantes, e não utilitaristas, mas que sustentem a convivência e o pleno desenvolvimento das sociedades.

Para que ocorra a efetivação de usos sociais mais compatíveis com a salvaguarda do patrimônio, em face a essa discussão, observamos a necessidade da participação dos cidadãos. A política de proteção do patrimônio no Brasil sempre foi aplicada de forma arbitrária, considerando a excepcionalidade e monumentalidade dos patrimônios e das áreas protegidas, e não dialogando na totalidade com os que são realmente afetados pelas leis. A participação democrática e cidadã, em nosso entendimento, perpassa por uma possibilidade de democracia participativa e até mesmo deliberativa (SMITH, 2003). Já que a pluralidade de opiniões fortalece o debate e tende a dialogar e a ouvir a opinião de todos os grupos sociais envolvidos.

O texto consiste em um ensaio teórico. Primeiramente, discutimos a noção de patrimônio cultural e patrimônio natural, juntamente com algumas considerações sobre os aspectos gerais das Unidades de Conservação da Natureza instituídas pelo poder público que visam cumprir diversas funções de caráter ambiental e de desenvolvimento sustentável (SNUC, 2000), mas que falham ao não se aprofundar sobre os conflitos socioambientais existentes quando da proteção integral das UCs.

Neste contexto, buscamos compreender também, como os riscos (BECK, 2006) promovem incertezas e complexidades cada vez maiores em nossa sociedade (MORIN, 2011). A escala dos problemas ambientais deveria ser considerada sobre a interação dos diferentes grupos sociais e políticos que são causadores de grande parte da degradação ambiental, mas que são também responsáveis pela solução. E estes problemas e ou desafios poderiam ser mais bem debatidos se houvesse mais participação democrática na tomada de decisões (LAFFERTY e MEADOWCROFT, 1998).

Como os problemas ambientais ultrapassam os limites territoriais, de Países, Estados e Municípios, a desconsideração dessas complexidades levam os governos a estabelecerem políticas locais que não necessariamente resolvem os desafios ambientais quando estes estão somente preocupados como suas próprias bases de crescimento econômico e interesses difusos, enquanto problemas ambientais e culturais são deixados de lado. Estes são bastante emblemáticos em se tratando da instituição 
de áreas protegidas no Brasil.

\section{PATRIMÔNIO NATURAL E ÁREAS PROTEGIDAS: QUESTÕES PARA REFLEXÃO}

As atividades humanas, sem dúvida alguma veem causando grandes transformações nas paisagens naturais. Para resguardar certas porções do território dessas transformações, a instituição de áreas protegidas tem sido uma prática recorrente (MORSELLO, 2001). Contudo, a simples criação de áreas protegidas no Brasil e no mundo não têm garantido a conservação destes espaços por si só. Com a necessidade de proteção, compreende-se a existência de riscos e as ameaças à sua conservação (DIXON e SHERMAN apud MORSELLO, 2011).

$\mathrm{O}$ avanço científico e tecnológico da sociedade teve como consequência a transformação dos ecossistemas de forma cada vez mais intensa e acelerada. Colocamos em risco a manutenção da vida no nosso planeta, ignorando a capacidade produtiva e regeneradora dos sistemas, nos obrigado a conviver com essas consequências, uma (BECK, 2006).

O avanço da destruição do meio ambiente e dos seus aspectos culturais e naturais, fez surgir preocupações cada vez mais urgentes quanto a necessidade de preservar a cultura e a natureza. Neste contexto, surgiram instrumentos de proteção ao patrimônio mundial, cultural e natural (UNESCO, 1972).

O patrimônio natural, a nosso ver, também é cultural. A definição de VarineBoham (1975) elucida bem este entendimento: em sua acepção, o patrimônio cultural está dividido em três categorias de elementos, sendo o primeiro, o natural, pois são os recursos naturais que tornam o espaço habitável. O segundo compreende as técnicas, o conhecimento, o saber e o saber-fazer, que são os elementos intangíveis do patrimônio cultural que garante a sobrevivência do homem no meio ambiente. 0 terceiro representa os objetos, os artefatos e as construções humanas que se originam da junção dos elementos naturais com o saber fazer adquiridos ao longo da história (VARINE-BOHAN, 1975 apud LEMOS 1981). Assim, estes três elementos devem ser considerados igualmente quando nos referimos ao patrimônio cultural.

A legislação de proteção referente ao patrimônio cultural no Brasil surgiu na década de 1930 por um decreto lei que se referia ao patrimônio histórico e artístico brasileiro, juntamente com leis que deliberavam sobre os bens considerados de grande valor cultural. Na mesma década surgiram as primeiras leis de proteção à natureza na forma de códigos; o código das águas, das minas, de proteção dos animais e o primeiro código florestal brasileiro de 1934 (IPHAN, 2004).

Dentro de uma perspectiva do patrimônio natural, é necessário entender, além dos riscos e ameaças, que as perdas são aquelas que comprometem sua manutenção, conservação e salvaguarda. As ameaças as quais o patrimônio está exposto, seja ele patrimônio natural ou cultural, são diversas. De acordo com o IPHAN (2004) há risco de desaparecimento do patrimônio, 
devido a degradação acelerada, empreendimentos de grande porte públicos ou privados, desenvolvimento urbano e turístico acelerados, destruições devida a mudanças de uso, alterações profundas por causas desconhecidas, abandono por qualquer motivo, conflito armado já iniciado ou latentes, calamidades ou cataclismos, incêndios, terremotos, deslizamentos de terra, erupções vulcânicas, modificação do nível das águas, inundações e maremotos (IPHAN, 2004).

Na mesma época foi criado o primeiro parque brasileiro (Parque Nacional do Itatiaia-RJ) inspirado no modelo Norte Americano de Yellowstone em Whyoming. Esta política, no caso brasileiro, estava direcionada basicamente à proteção da flora e da fauna, mas também já considerava a proteção da beleza cênica e paisagística das áreas naturais (MORSELLO, 2001; IPHAN, 2004). Nesta época, a monumentalidade e a excepcionalidade do bem eram consideradas para sua proteção, tanto na esfera cultural como dos monumentos naturais.

Neste contexto, surgiram os bens classificados nas duas categorias, assim foi criada a classificação de bem misto, inscritos por critérios naturais e culturais, mas sem uma análise da integração entre ambos (SANTILLI, 2010), que são as paisagens culturais. Em 1992, no ano em que se realizou a Conferência das Nações Unidas sobre Meio Ambiente e Desenvolvimento, no Rio de Janeiro, que a Unesco adotou a categoria "paisagem cultural", com um propósito de valorizar todas as inter-relações entre homem e o meio ambiente, entre o natural e o cultural (SANTILLI, 2010).

Muito embora a natureza e a cultura brasileiras já estivessem resguardadas por leis, a Constituição Federal (CF) de 1988 inovou e abarcou o interesse pelo patrimônio cultural e natural de forma conjunta. Os artigos 215 e 216 da CF declaram que o patrimônio cultural brasileiro compreende os conjuntos urbanos e os sítios naturais. Segundo a definição:

Constituem o patrimônio cultural brasileiro, os bens, de natureza material e imaterial, tomados individualmente ou em conjunto, portadores de referência à identidade, à ação, à memória dos diferentes grupos formadores da sociedade brasileira, nas quais se incluem as formas de expressão; os modos de criar, fazer e viver; as criações científicas, artísticas e tecnológicas; as obras, objetos, documentos, edificações e demais espaços destinados às manifestações artístico culturais; os conjuntos urbanos e sítios de grande valor histórico paisagístico, artístico, arqueológico, paleontológico, ecológico e científico (CF, 1988).

No caso das áreas protegidas, segundo a legislação brasileira, elas podem ser públicas ou privadas. Para Morsello (2001, p. 15) "são áreas que se aplicam medidas restritivas de uso do solo, com a função de proteger certa feição natural ou histórica presente no local". Com esta definição podemos aferir a relação entre a natureza e a cultura implícita na necessidade de criação das Unidades de Conservação segundo 
esta autora.

Uma Unidade de Conservação no Brasil, de acordo com a Lei Federal n.ㅇ 9.985/2000, que regulamenta o Sistema Nacional de Unidades de Conservação consiste em:

\begin{abstract}
Um espaço territorial e seus recursos ambientais, incluindo as águas jurisdicionais, com características naturais relevantes, legalmente instituído pelo Poder Público, com o objetivo de conservação e limites definidos, sob regime especial de administração, ao qual se aplicam garantias adequadas de proteção (SNUC, 2000).
\end{abstract}

Esta definição ressalta o aspecto ambiental na instituição das áreas protegidas e seu objetivo de conservação de espaços com relevantes atributos naturais. Não obstante as definições, notamos que no caso das UCs é conferido certo destaque aos seus aspectos ecológicos e de conservação/preservação da biodiversidade, não as considerando como um patrimônio cultural que ao longo dos anos, no Brasil resultaram em casos na proibição ou regulação de atividades básicas e de subsistência como a pesca, o extrativismo e a caça de populações que já habitavam as áreas protegidas.

Ainda que na esfera do patrimônio o meio ambiente tenha certo destaque, principalmente pelas considerações tomadas após a convenção da UNESCO (1972). A CF brasileira reverbera que a competência da gestão do patrimônio cultural e natural são de responsabilidade dos órgãos da cultura. Mas a mesma constituição no capítulo sobre o meio ambiente dá a responsabilidade da instituição de áreas protegidas aos órgãos ambientais a fim de garantir um meio ambiente ecologicamente equilibrado e também a responsabilidade de gestão das Unidades de Conservação (CF, 1988; IPHAN, 2004).

Este fato oferece uma dificuldade de compreensão sobre a responsabilidade pela proteção do patrimônio cultural (natural) representado pelas Unidades de Conservação. Pois nota-se que os órgãos da cultura não atuam em conjunto com os organismos ambientais, e os órgãos ambientais nem sempre entendem as Unidades de Conservação como um patrimônio cultural brasileiro, dando à estes espaços uma conotação apenas preservacionista pelos seus aspectos ecológicos desconsiderando suas relações com a cultura, principalmente com as comunidades que habitam estes espaços.

A presença de populações em áreas protegidas é uma regra e não uma exceção no contexto brasileiro e mundial. Nesse sentido, a relação entre populações e a criação de áreas protegidas foi sempre muito conflitosa. Normalmente há uma imposição das Unidades de Conservação para dar respostas ás políticas ambientais de conservação da biodiversidade sem considerar que existem habitantes (tradicionais ou não) há muito tempo residindo e desenvolvendo sua vida social nestes espaços. Pois não há, ou há pouca participação na tomada de decisão, assim como na gestão e na pósimplantação das áreas protegidas, aonde os planos de manejo também se apresen- 
tam pouco participativos.

Estes conflitos são inerentes das complexidades e dos desafios ambientais de nossa época (MORIN, 2011), e nesse sentido, identificamos que o preservacionismo no trato com o patrimônio natural não garante de fato, a proteção destes bens tão importantes para todos, mas principalmente para os que habitam as áreas protegidas.

\section{USOS SOCIAIS DO PATRIMÔNIO E PARTICIPAÇÃO DEMOCRÁTICA}

A patrimonialização dos símbolos da cultura e da natureza não garantem por si só a sua conservação e salvaguarda. Os lugares de grande valor, na representação da identidade das diferentes formas de sociedade são recorrentemente transformados em símbolos que remetem a certa identidade, que nem sempre é aceita, mas imposta.

Para pensar na salvaguarda do patrimônio cultural é preciso, antes de tudo, considerar as suas funções sociais (GARCIA-CANCLINI, 1999; ZANIRATO, 2009), seus usos para a efetividade de sua proteção. Zanirato $(2009$, p.138) afirma que a proteção do patrimônio "se efetiva com o envolvimento da comunidade que o detém, num processo que inclui a identificação, a conservação, o estudo e a difusão dos bens patrimoniais". O patrimônio cultural não pode ser dissociado da relação entre seu passado histórico e as necessidades da comunidade no presente. Existe aí, portanto, uma relação complexa entre o imperativo da proteção e a necessidade de uso desses bens.

Outro aspecto a ser levado em consideração é a representação do patrimônio para determinada comunidade, ou seja, se ela se identifica naquele bem e de que maneira ela pode usufruir desse patrimônio? Isso ocorre, em parte, pelo entendimento que o bem patrimonial remete a um tempo histórico passado ou de certa monumentalidade, e que por isso, deve ser preservado, mas que a comunidade local, no tempo presente, usualmente não se identifica com a história, nem com o bem patrimonial, sendo estes um ônus, onde as comunidades se sentem prejudicadas com a ineficiência das políticas de salvaguarda, que por um lado protegem o bem e por outro não oferecem alternativa de usos desse patrimônio.

Nesse sentido, a noção de patrimônio precisa ser socialmente construída através da valorização dos bens e na difusão da importância de sua preservação. Para Zanirato:

Os conhecimentos, crenças e gostos dependem do modo como os grupos sociais acessam o que é considerado bem. Por isso, não é raro que objetos e saberes gerados pelos grupos que têm maior informação e formação acabem por ser majoritariamente considerados como bens patrimoniais. Esses grupos não só definem o que é digno de conservação, como ainda dispõem de condições para atribuir maior qualidade e refinamento a esse mesmo bem (ZANIRATO, 2009, p. 139). 
Se a comunidade não se identifica com o patrimônio, como fazer para que ela contribua para sua salvaguarda? Zanirato (2009), a luz desta discussão, diz que o desafio de lidar com o patrimônio é fazer com que a preocupação com a salvaguarda seja compartilhada com o maior número de pessoas possível, que envolveria uma grandiosa participação social. Nesse sentido, a não participação nas tomadas de decisão, historicamente,

contribuiu para corporificar uma forma de conceber o patrimônio como uma prática social da qual (a sociedade de forma geral) não participa. A política patrimonial é vista como uma política de especialistas, que têm a capacidade de decidir sobre o valor e a relevância do que deve ser salvaguardado (ZANIRATO, 2009, p. 141).

O tombamento do patrimônio material ou a instituição de áreas protegidas por órgãos oficiais nos dá a impressão que essa ação pode significar o reconhecimento do valor histórico e/ou natural pela comunidade, mas após a proteção, não se veem investimentos para a efetiva salvaguarda do patrimônio. Sobre esta questão, Gagliardi afirma que:

O limite entre o reconhecimento e o descaso é tão tênue que, somado aos demais aspectos que impedem que seja geral o sentimento de pertencimento àquela memória, reforça sentido de lugar sem valor, de uma cidade histórica não reconhecida como tal (GAGLIARDI, 2005, p.14).

Portanto, é necessária a formulação de políticas públicas em que a utilização do patrimônio cultural e natural considere as necessidades da comunidade e da localidade, e não somente da proteção em si, em que todos tenham participação na tomada de decisão sobre as políticas de uso e conservação, ainda que essa não seja a prática mais comum na política de proteção ao patrimônio no Brasil.

Usualmente, o turismo se apresenta como uma prática social que pode contribuir para a conservação, salvaguarda e uso mais adequado do patrimônio cultural e natural, desde que atenda as necessidades e anseios da comunidade local, que valorize a identidade e a memória, bem como o meio ambiente e que possa contribuir positivamente para a salvaguarda do patrimônio, já que se utiliza do próprio bem para valorizar a história e a cultura para a conservação de determinado local.

Mas ressaltamos também, que o patrimônio é apropriado pelo turismo e promove a transformação dos territórios e as formas de uso desse patrimônio. A atividade do turismo introduz no espaço novos objetos, e objetos já existentes são absorvidos pelo turismo, fato que para Cruz (2003) altera significativamente o sentido destes objetos, com o simples intuito de atender a demanda de uso turístico. Doutro lado, verifica-se que muitos bens culturais da humanidade, foram salvos graças a valorização permitida pelo turismo (BENI, 2004).

O turismo pode ser um uso social para a salvaguarda do patrimônio, desde que a- 
tendido as condições de cada localidade e da comunidade. Contudo, é preciso pensar em outras atividades para a compatibilizar os usos e a proteção das áreas protegidas. Para GARCIA-CANCLINI (1999), algumas questões devem ser levantadas para pensar os usos sociais do patrimônio, tais como: o patrimônio e a desigualdade social; os usos deste patrimônio; os propósitos da preservação e o patrimônio na era da industria cultural, em que todas as formas de usos devem considerar, antes de tudo a participação social.

Outros usos devem ser socialmente compartilhados com os cidadãos. Uma forma de democracia deliberativa, por exemplo, pode tornar o poder de decisão e a participação política da sociedade em teoria mais próxima da esfera pública, e não apenas por meio do voto. Ainda que as instituições liberais não são propensas a encorajar movimentos democráticos tão participativos é preciso engajar a participação dos cidadãos nas tomadas de decisões públicas (SMITH, 2003).

Alguns exemplos de usos compatíveis com as características das Ucs brasileiras, considerando o fato que em sua grande maioria existe população no interior e ao redor são os pagamentos por serviços ambientais (PARRON et al, 2015), onde até mesmo o governo poderia obter recursos, pois com a criação de áreas protegidas o Estado "beneficia" as empresas que "vendem" os recursos naturais, como a água, além de promover a melhoria de outros serviços ecossistêmicos.

A agroecologia e a agricultura orgânica também poderiam contribuir para a salvaguarda do patrimônio natural, desde que planejado e que considere ás necessidades das comunidades. Além disso, os já conhecidos propósitos de muitas áreas protegidas que são a pesquisa cientifica e a educação ambiental, que têm que ser melhor trabaIhados.

Para que esse propósito seja efetivo, é preciso que envolva um engajamento na participação social. Lafferty e Meadowcroft, (1998), explicam que a escala dos problemas ambientais tem que ser considerada sobre a responsabilidade dos diferentes grupos sociais e políticos que são causadores de grande parte da degradação ambiental, mas que também são partes essenciais da solução, ou seja, deve ser considerado por todos os grupos sociais (SMITH, 2003).

Um dos principais argumentos da democracia deliberativa para Smith (2003) consiste no diálogo como forma de dar legitimidade as decisões pelos cidadãos que são livres para decidir. Porem, a instrumentalização estratégica das decisões pelos grupos de poder inviabilizam a participação cidadã. Nem sempre estes grupos fazem questão da participação social e política mais igualitária.

No entanto, não há garantias de que a livre discussão irá garantir mais valor ao mundo natural (não humano). Não há garantias fieis de que os tomadores de decisão irão considerar os problemas ambientais ainda que sejam bem evidentes, por causa das incertezas que os cercam e devido às pressões externas. Não há, portanto, ao meu ver, uma conexão dos problemas ambientais com a democracia deliberativa, mas a discussão deliberativa dos problemas pode ser um caminho valioso. 
É razoável a ideia de que a nossa tradição liberal democrática continue sendo a forma política mais aceita nos países democráticos. Mas "esverdear" ou sensibilizar aos tomadores de decisão é um passo importante na construção do debate sobre todas estas complexas questões.

A pluralidade da opinião pública fortalece o debate. Dentro da sociedade civil estão as demandas mais latentes, ouvi-las, numa democracia participativa é muito importante e vai de encontro com os preceitos da democracia deliberativa, onde a voz da sociedade é considerada. Ainda mais quando falamos na pluralidade dos problemas e das prioridades ambientais e de salvaguarda do patrimônio.

No caso das áreas protegidas, principalmente as de proteção integral, onde as atividades são restritivas, se veem poucas alternativas de desenvolvimento para as comunidades que dentro destas áreas estão localizadas, não se estima, ou não é uma prática a possibilidade da participação democrática frete aos desafios a as complexidades inerentes às relações homem-natureza. É preciso, como foi dito no decorrer do texto, que se busquem alternativas de usos mais adequados ás realidades socioculturais, e econômicas nas áreas protegidas no Brasil.

\section{CONSIDERAÇÕES FINAIS}

Este ensaio buscou demonstrar, em parte, que as ameaças e os riscos ao desaparecimento do patrimônio natural, que também contém o cultural surgem da ideia preservacionista que ainda constitui a política de salvaguarda das áreas protegidas, que são o patrimônio das diferentes comunidades que vivem próximas ou até mesmo dentro das Unidades de Conservação no Brasil.

O modelo de Unidade de Conservação de Proteção Integral apresenta vantagens e desvantagens. Por um lado, é uma forma de preservar a natureza em seus aspectos físicos e biológicos mais relevantes, mas por outro, a existência de inúmeras comunidades que vivem nestes espaços protegidos, instituídos muito depois das chamadas "populações tradicionais". Por este motivo, muitas vezes, o patrimônio cultural e natural ficam ameaçados pela falta de possibilidades de desenvolvimento.

Normalmente a política ambiental das Unidades de Conservação impuseram restrições e mudanças no regime de uso do espaço e dos recursos naturais, o que transforma as comunidades afetadas e limita seus modos de vida. Por este motivo, expomos a ideia central do texto que são os usos sociais possíveis para que se efetive a salvaguarda do patrimônio e promove de certa medida o desenvolvimento socioeconômico.

Mas para que isso seja possível, é necessário que haja a participação democrática na tomada de decisão e que todos sejam considerados. No texto, utilizamos de alguns autores como Smith (2003) e Lafferty e Meadowcroft, (1998) para demonstrar que a participação democrática e deliberativa pode ser uma alternativa de gestão das áreas protegidas. 
Identificamos que é necessário a participação social para a efetivação da proteção do patrimônio cultural e natural, mas ainda estamos longe de que isso se torne realidade, pois a participação social e os interesses dos que detém caminham em direções opostas no Brasil. Para a proteção do patrimônio se efetivar, os diferentes agentes sociais devem ter participação ativa na identificação e salvaguarda do patrimônio.

\section{BIBLIOGRAFIA}

BENI, Mario Carlos. Análise estrutural do turismo. São Paulo. SENAC, 2004.

BECK, Ulrich. La sociedad del riesgo. Barcelona: Paidós, 2006.

CRUZ, Rita de Cássia Ariza da. Introdução à geografia do turismo. São Paulo, Roca, 2003.

GAGLIARDI, Clarissa Maria Rosa. As cidades do meu Tempo: a experiência do turismo em Bananal. Dissertação (Mestrado) (2005) PUC São Paulo.

LAFFERTY W. M. e MEADOWCROFT J. Democracy and the Environment: Problems and Prospects Edward Elgar, United Kingdon, 1998.

GARCIA-CANCLINI. Néstor. Los usos sociales del patrimonio cultural. En: Encarnación, Patrimonio Etnológico. Nuevas perspectivas de estudio. España: Consejería de Cultura, Junta de Andalucía, 1999.

IPHAN, O Patrimonio Natural no Brasil, Brasília, 2004. disponível em: portal.iphan.gov.br/uploads/publicacao/Patrimonio_Natural_no_Brasil.pdf

MORIN, Edgar. Introdução ao pensamento complexo.Rio de Janeiro: Bertrand Brasil, 2011.

MORSELLO, C. Áreas Protegidas Públicas e Privadas: Seleção e Manejo. São Paulo, Annablume/FAPESP, 2001.

PARRON, M. L. Serviços ambientais em sistemas agrícolas e florestais do Bioma Mata Atlântica. Parron, L. M. [et al.], Brasília, DF : Embrapa, 2015.

SANTILLI, J. Paisagens culturais, ISA - Instituto Socioambiental, 2010. Disponível em https://uc.socioambiental.org/\%C3\%A1reas-de-patrimonio-cultural/paisagens-

culturais. Acesso em 25/11/2016.

SMITH, G. Deliberative Democracy and the Environment London, Routledge, 2003.

SNUC. Sistema Nacional de Unidades de Conservação. Lei Federal $n$ ㅇ 9.985 de 18 de julho de 2000

UNESCO. Convenção para o patrimônio mundial, cultural e natural, ONU, 1972.

ZANIRATO, Silvia Helena. Usos sociais do patrimônio cultural e natural UNESP - FCLAs - CEDAP, v. 5, n.1, p. 137-152 - out. 2009.

Artigo recebido em 31 de maio de 2017.

Aprovado em 26 de julho de 2017. 